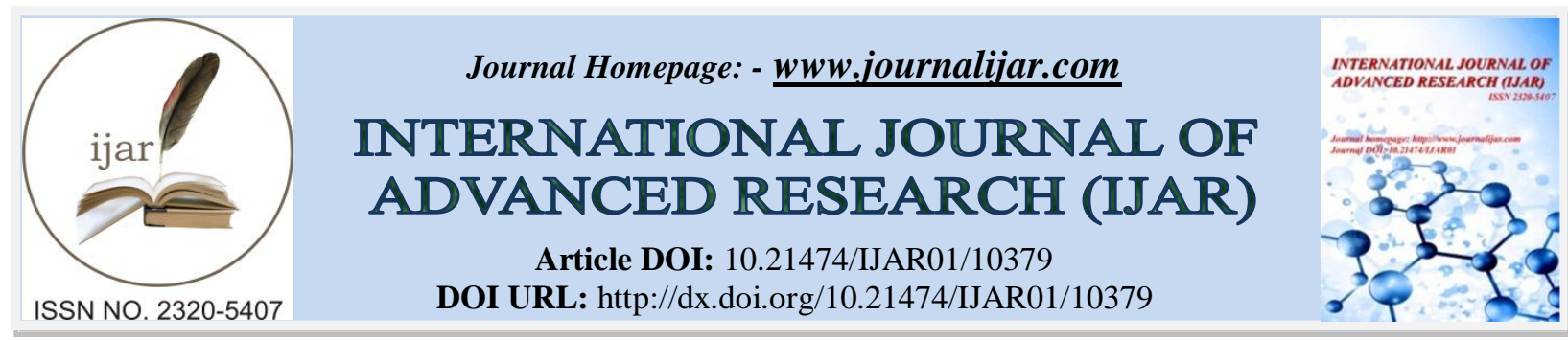

RESEARCH ARTICLE

\title{
EFFECTIVENESS OF MINDFULNESS BASED COGNITIVE THERAPY VERSES CONVENTIONAL PHYSIOTHERAPY ON KINESIOPHOBIA IN PATIENTS WITH OSTEOARTHRITIS OF KNEE: A COMPARATIVE STUDY
}

\author{
Srushti Ramesh Gujare ${ }^{1}$ and Dr. Pradeep Borkar ${ }^{2}$ \\ 1. Intern, Dr, A.P.J Abdul Kalam College of Physiotherapy, Pims-Du, Loni, India. \\ 2. Asst. Prof, Dr, A.P.J Abdul Kalam College of Physiotherapy, Pims-Du, Loni, India.
}

\section{Manuscript Info}

Manuscript History

Received: 30 November 2019

Final Accepted: 31 December 2019

Published: January 2020

Key words:-

Osteo-Arthritis Knee, Kinesiophobia,

Tampa Scale For Kinesiophobia,

Mindfulness Based Cognitive Therapy

\begin{abstract}
Background: Knee osteoarthritis (OA) is a clinical condition with the pathological findings of degeneration of the joint cartilage, subchondral sclerosis, and osteophyte formation, presents with pain and stiffness in the joints, which causes loss of function and restrictions in activities of daily living.Mindfulness-based interventions have lately been shown to be effective for the treatment of chronic pain with small to moderate effect sizes on pain and depression (Veehofetal.,2011). While pain has both physical and psychological components, MBCT may address chiefly the psychological components, by minimizing reactions to physical pain, such as worrying, catastrophizing, avoidance, and selfblaming.

Aim: The present study was taken for comparison between Effect of mindfulness based cognitive therapy versus conventional physiotherapy on levels of kinesiophobia in patients with osteoarthritis of knee

Method: The study was a comparative study where effect of Mindfulness based cognitive therapy was given along with conventional therapy in randomly divided two MBCT along with conventional therapy (group A) and conventional therapy (group B). Total 30 samples were given treatment for 8 weeks and the data was collected and analyzed on Tampa scale for kinesiophobia. The results were analyzed using unpaired and paired t test.

Result: The comparison of mean post intervention scores for group A and B of TSK Scores was found to be statistically significant which was calculated using un-paired $t$ test with $t$ value $t=3.603$, degrees of freedom $\mathrm{df}=28$ and $\mathrm{p}$ value $\mathrm{p}=0.0012$.

Conclusion: 8 weeks of MBCT given with conventional therapy has shown to reduce levels of kinesiophobia on TSK scale. Thus, MBCT should be considered to be given along with conventional treatment in patients of OA knee who have high levels of kinesiophobia
\end{abstract}

Copy Right, IJAR, 2020,. All rights reserved.

\section{Introduction:-}

Knee osteoarthritis (OA) is a well-known disease of the older population and one of the important causes of disability. Some of the general risk factors of knee OA are age, over-weight, trauma to joint due to repetitive 
movements specifically squatting and kneeling ${ }^{(1)}$ Rosemann et al conducted a cross-sectional survey in 1,021 patients with OA and reported that psychological factors (such as anxiety and depression) were highly prevalent among the patients $(19.76 \%$ of male and $19.16 \%$ of female participants reported a PHQ-9 score of $\geq 15) .{ }^{(2)}$ OA patients experience significant increases in joint stress and load forces on the knees, which causes increased pain. The increased pain that occurs during movement often leads to a restricted and physically inactive lifestyle adopted to avoid pain, which eventually will lead to additional weight gain, and increased pain and disability. ${ }^{(3)}$

The word kinesiophobia was introduced in 1990 by Kori, Miller, and Todd. Kinesiophobia is a condition in which a patient has "an increased, irrational, and enfeebling fear of physical movement and activity resulting from a feeling of vulnerability to painful injury or reinjury'. The Tampa Scale for Kinesiophobia (TSK) was presented in 1991 by Miller, Kori, and Todd. The original version of the TSK in American English has been widely used ${ }^{(4)}$.The prevalence of kinesiophobia in persistent pain ranges from $50 \%$ to $70 \%{ }^{(5)}$

MBCT places little stress on changing or altering thought content; rather, by focusing on part takers awareness of their relationship to their thoughts and feelings, itgoalsto improve metacognitive awareness. ${ }^{(6)}$. MBCT is a assuring intervention for individualssearchingtreatment in primary health care settings who are experiencing increased levels of psychological distress in the circumstancesof chronic illness and/or other stressful health-related challenges ${ }^{(7)}$.

A valuable commonly believed mechanism of action of MBCT is to improve metacognitive awareness by inspiring participants to adopt a distinct mode of being. Another important mechanism of action of MBCT may be to enhance the ability to intentionally redistributeone's attention, allowing for more flexible cognitive and behavioral responses (6). The practice of mindfulness and other module elements of the MBCT programme have 4 broad learning intentions in relation to the processes leading to depressive relapse.Participants learn to develop ability to step out of ruminative thinking pattern, recognize and be aware of potential relapse-related modes of processing, access new ways to relate to both depression-related and other experiences and turn towards, befriend and compassionately hold all aspects of experiences ${ }^{(8)}$.

MBCT may be an effective intervention for the treatment of active depression in a population with chronic pain ${ }^{(9)}$. The treatment goal of MBCT program and psychotherapeutic interventions of chronic pain in general, is not to remove or reduce the pain itself, but rather to find ways of managing the pain and the adverse consequences on mental health and quality of life ${ }^{(10)}$.

Considering that in patients with knee OA, treatment of pain alone is not enough to reduce fear of movement, approaches towards other treatment strategies along with the existing treatment methods for knee OA to overcome this fear should be discovered and included in the treatment program.

\section{Procedure:}

Prior to the commencement, this study was approved by the Ethical Committee at Dr. APJ Abdul Kalam College of Physiotherapy at Pravara Institute of Medical Sciences. The study was introduced after all the patients were informed about the research procedure. Detailed information regarding the nature of study was given to the patients before participation. Written consent forms were taken from the patients and permissions obtained. Those patients fulfilling the inclusion criteria were requested to participate in the study. All the patients were assessed for the levels of kinesiophobia with the help of Tampa scale of kinesiophobia (TSK) which was translated to them in marathi and the score was calculated those patients who had a final TSK score of 38 or above were included in the study. The 30 subjects selected were diagnosed cases of stage 2 osteoarthritis knee and who have a BMI values ranging between 18.90 to 24.99 according to WHO classification. The selected subjects then were randomly divided into two groups. Group A (MBCT) and Group B (Conventional therapy). All the participants in group A were given mindfulness based cognitive therapy along with conventional physiotherapy for 8 weeks. Simultaneously all the participants in group B were given conventional physiotherapy for 8 weeks. After 8 weeks of this intervention all the participants were re-assessed using the TSK scale and their scores were noted and compared to those taken pre-intervention.

\section{Intervention:}

The conventional physical therapy protocol administered in Group B was as follows:

1. Short wave diathermy (crossfire method) for 15 minutes.

2. Static quadriceps.

3. High sitting knee extension. 
4. Straight leg raise.

5. Hamstring stretching.

6. Hip abduction.

7. Hip extension.

In the Group A i.e. the intervention group, MBCT technique was added to study its effect. MBCT sessions were given immediately after the conventional exercises. Exercises given in MBCT sessions were rasin exercises, body scan meditation, 10 minutes mindful breathing, mindful movement, stretch and breath practice, 3 minute breathing space, sitting meditation, thoughts and feelings exercise ${ }^{(8)}$.

\section{Data Analysis and Results:-}

Demographics:

A total of 30 participants were selected according to the selection criteria. They were divided onto two groups according to randomization: group A (Mindfulness based cognitive-therapy with conventional physiotherapy) and group B (conventional physiotherapy only).

Table 1:- Age Distribution.

\begin{tabular}{|l|l|l|}
\hline Demographics & Group a & Group b \\
\hline Mean age & $57.333 \pm 5.864$ & $56.36 \pm 5.623$ \\
\hline
\end{tabular}

Table 2:- Gender Distribution.

\begin{tabular}{|l|l|l|l|}
\hline Demographics of gender & Males & Females & Ratio (m: f) \\
\hline Group A & 6 & 9 & $2: 3$ \\
\hline Group B & 5 & 10 & $1: 2$ \\
\hline
\end{tabular}

Table 3:- BMI Distribution.

\begin{tabular}{|l|l|l|}
\hline Demographics of BMI & Group a & Group b \\
\hline Mean BMI & $23.64 \pm 0.91$ & $23.582 \pm 0.913$ \\
\hline
\end{tabular}

Table 4:- Comparison of pre-intervention and post-intervention TSK scores in Group A:

\begin{tabular}{|l|l|l|l|l|}
\hline $\begin{array}{l}\text { Outcome } \\
\text { measure }\end{array}$ & $\begin{array}{l}\text { Pre-intervention mean } \\
\text { + standard deviation }\end{array}$ & $\begin{array}{l}\text { Post-intervention mean }+ \\
\text { standard deviation }\end{array}$ & Paired t test & P value and significance \\
\hline Tsk score & $45.27 \pm 3.369$ & $33.866 \pm 2.748$ & $\mathrm{t}=18.754 \mathrm{df}=14$ & $\mathrm{P}=0.0012$, very significant \\
\hline
\end{tabular}

The above table shows comparison of mean of pre and post intervention scores of group A of TSK Scores which was found to be statistically significant calculated by using paired $t$ test shows that the study is very significant with $t$ value $t=18.754$, degrees of freedom $\mathrm{df}=14$ and $\mathrm{p}$ value $\mathrm{P}=0.0012$

Table 5:- Comparison of pre-intervention and post-intervention TSK scores in Group B:

\begin{tabular}{|l|l|l|l|l|}
\hline $\begin{array}{l}\text { Outcome } \\
\text { measure }\end{array}$ & $\begin{array}{l}\text { Pre- intervention mean } \\
\text { +standard deviation }\end{array}$ & $\begin{array}{l}\text { Post-intervention mean }+ \\
\text { standard deviation }\end{array}$ & Paired t test & P value and significance \\
\hline Tsk score & $44.266 \pm 2.789$ & $37.533 \pm 2.825$ & $\mathrm{t}=13.949 \mathrm{df}=14$ & $\mathrm{P}=0$-0003, very ignificant \\
\hline
\end{tabular}

The above table shows comparison of mean of pre and post intervention scores of group B of TSK Scores was found to be statistically significant calculated by using paired t test shows that the study is very significant with $t$ value $\mathrm{t}=13.949$, degrees of freedom $\mathrm{df}=14$ and $\mathrm{p}$ value $\mathrm{P}=0.0003$

Table 6:- Comparison of post-intervention TSK scores in Group A and Group B:

\begin{tabular}{|l|l|l|l|l|}
\hline $\begin{array}{l}\text { Outcome } \\
\text { measure }\end{array}$ & $\begin{array}{l}\text { Post -intervention mean } \\
\text { +standard deviation }\end{array}$ & $\begin{array}{l}\text { Post-intervention mean } \\
\text { + standard deviation }\end{array}$ & $\begin{array}{l}\text { Un-Paired } \\
\text { test }\end{array}$ & P value and significance \\
\hline Tsk score & $33.866 \pm 2.748$ & $37.533 \pm 2.825$ & $\mathrm{t}=3.603 \mathrm{df}=28$ & $\mathrm{P}=0.0012$, very significant \\
\hline
\end{tabular}

The above table shows comparison of mean post intervention scores for group A and B of TSK Scores was found to be statistically significant calculated using paired t test with $t$ value $t=3.603$, degrees of freedom $\mathrm{df}=28$ and $\mathrm{p}$ value $\mathrm{P}$ $=0.0012$. 


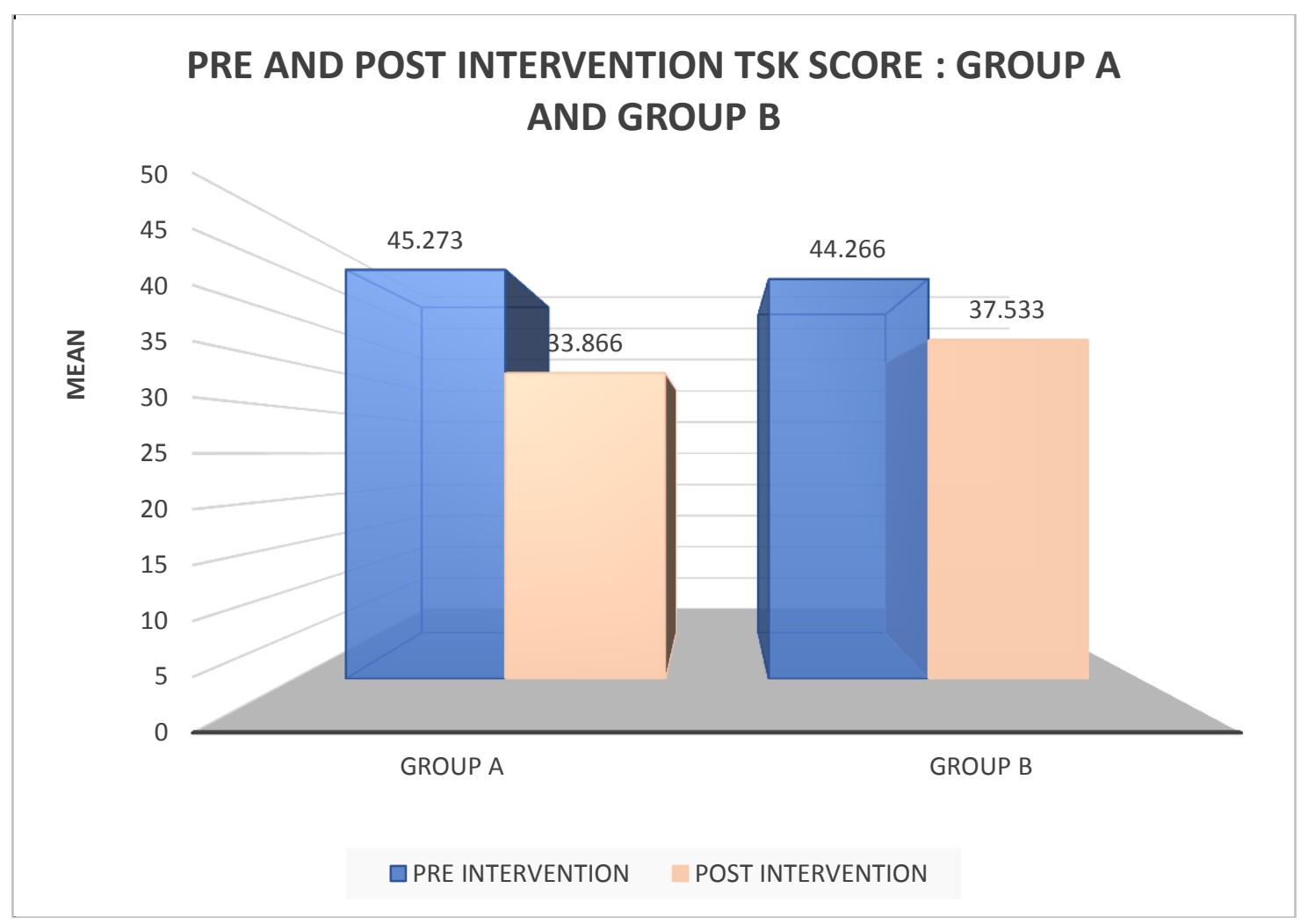

\section{Disscussion:-}

The current study was aimed to compare the effectiveness of mindfulness based cognitive therapy versus conventional physiotherapy on kinesiophobia in patients with osteoarthritis of knee.

There has been increasing recognition of the fact that the fear of pain linked to painful or harmful activities is an essential cognitive factor in relation to chronic pain, disability, anxiety, depression and effectiveness of treatment in knee OA patients ${ }^{(\mathbf{1 1})}$. According to a study conducted by Julio Domeneech et al for Influence of kinesiophobia and catastrophizing on pain and disability in anterior knee pain, patients showed significant participation of catastrophizing, kinesiophobia, anxiety, and depression in the functional impairment of anterior knee pain patient (12). Fear of movement may be considered as one phenomenon within a framework of a Fear- Avoidance Theory. The principle is that the experience of pain leads to fear, which in turn leads to avoidance behavior, such as avoiding movements linked with physical activity during daily life, exercise, or work activities ${ }^{(13)}$. In accordance to article by Emily L et al on pain related fear disability and fear-avoidance model of chronic pain stated researches have begun to adapt cognitive behavioral treatments for fear and anxiety in treatment of pain related fear. Also exposure based plan of action are reviewed as gold standard treatments for certain phobias (i.e fear cued by anticipation of an object or situation) and typically comprise provision of adaptive coping strategies and exposure to feared situations or objects ${ }^{(14)}$. In current study, the group A was given MBCT technique along with conventional physiotherapy. After comparing the pre and post intervention scores of group A of outcome measure TSK scale the patients showed reduced levels of kinesiophobia after undergoing MBCT along with conventional treatment. The theories projected behind this intervention are to evolve an ability to re-center or step back from ruminative thought process. MBCT participants learn to be able to relate characteristics of experience and ruminative thought patterns in specific from a de-centered outlook. De-centering includes developing the capacity to not to be identified or lost within experience for instance seeing thoughts as thoughts rather than portrayal of reality ${ }^{(8)}$. Similarresults were obtained in a study conducted by Abdolghaderi $\mathrm{M}$ et al titled effectiveness of MBCT and CBT on decreasing Pain, depression and anxiety of patients with chronic low back pain which concluded MBCT and CBT were very effective in decreasing pain, depression and anxiety ${ }^{(15)}$.

In current study Group B was given conventional physiotherapy exercises which also showed reduced levels of kinesiophobia after comparing pre and post-intervention scores of group B assessed with the help of TSK scale. 
Similar results were obtained from a previous study done by, Helmhout et al which investigated the influence of exercise alone on TSK scores. Their intervention consisted of 14 sessions comprised of 10 minutes of backstrengthening exercise, comparing low- versus high-intensity protocols. The high-intensity training group showed a greater strength gain $(24-58 \mathrm{Nm})$ and a lesser decline in fear of movement (2.5-3.4 points less), compared to the low-intensity training group ${ }^{(16)}$. In current study comparison of the effectiveness of mindfulness based cognitive therapy versus conventional physiotherapy on kinesiophobia in patients with osteoarthritis of knee was done which statistically showed that MBCT combined with conventional physiotherapy was more effective in treating kinesiophobia with $(\mathrm{t}=3.603, \mathrm{df}=28)$. The results of the study were also supported with the study done by $\mathrm{M}$ MVeehoof et al. Where Twenty-five randomized controlled trials (RCTs) were included in this meta-analysis. At post treatment, small outcome was found for pain intensity, depression, disability and quality of life; and moderate effects for anxiety and pain-interference ${ }^{(17)}$. Comparing the post interventional TSK scores of both the groups, the study proved that both the interventions were statistically significant in reducing TSK scores and were effective in reducing levels of kinesiophobia but Group A participants showed more effective results in reducing the levels of kinesiophobia compared to group B as group A participants received both the conventional and MBCT treatment the participants showed greater reduction in the levels of kinesiophobia. Thus, we conclude that along with the conventional physiotherapy interventions for OA knee, Mindfulness based cognitive therapy should also be taken into consideration in order to reduce the levels of kinesiophobia and improve quality of life in such patients.

\section{Conclusion:-}

We concluded that Mindfulness based cognitive therapy given with conventional physiotherapy for 8 weeks was more effective than just conventional therapy in reducing the levels of kinesiophobia in patients with osteoarthritis of knee according to the scores calculated with the help of Tampa scale for kinesiophobia (TSK). Thus, MBCT should be considered to be given along with conventional treatment in such patients.

\section{Limitations:}

1. The study did not include patients who were overweight and obese.

2. As the study was time bound the sample size was limited

\section{Scope of the study:}

1. Further studies involving the said intervention of MBCT can be carried out in individuals who are obese.

\section{Clinical implications:}

MBCT can be introduced along with conventional treatment to treat patients with OA knee who have increased levels of kinesiophobia.

\section{Referrences:-}

1. Heidari B. Knee osteoarthritis prevalence, risk factors, pathogenesis and features: Part I. Caspian journal of internal medicine. 2011;2(2):205.

2. Sharma A, Kudesia P, Shi Q, Gandhi R. Anxiety and depression in patients with osteoarthritis: impact and management challenges. Open access rheumatology: research and reviews. 2016;8:103.

3. Somers TJ, Keefe FJ, Carson JW, Pells JJ, LaCaille L. Pain catastrophizing in borderline morbidly obese and morbidly obese individuals with osteoarthritic knee pain. Pain Research and Management. 2008;13(5):401-6.

4. Lundberg MK, Styf J, Carlsson SG. A psychometric evaluation of the Tampa Scale for Kinesiophobia-from a physiotherapeutic perspective. Physiotherapy theory and practice. 2004 Jan 1;20(2):121-33.

5. Luque-Suarez, A., Martinez-Calderon, J. and Falla, D., 2019. Role of kinesiophobia on pain, disability and quality of life in people suffering from chronic musculoskeletal pain: a systematic review.Br J Sports Med,53(9), pp.554-559.

6. Sipe WE, Eisendrath SJ. Mindfulness-based cognitive therapy: theory and practice. The Canadian Journal of Psychiatry. 2012 Feb;57(2):63-9.

7. McCay E, Frankford R, Beanlands H, Sidani S, Gucciardi E, Blidner R, Danaher A, Carter C, Aiello A. Evaluation of mindfulness-based cognitive therapy to reduce psychological distress and to promote well-being: a pilot study in a primary health care setting. SAGE Open. 2016 Sep;6(3):2158244016669547.

8. Crane R. Mindfulness-based cognitive therapy: Distinctive features. Routledge; 2017 Sep 19

9. de Jong M, Lazar SW, Hug K, Mehling WE, Hölzel BK, Sack AT, Peeters F, Ashih H, Mischoulon D, Gard T. Effects of mindfulness-based cognitive therapy on body awareness in patients with chronic pain and comorbid 
depression. Frontiers in psychology. 2016 Jun 30;7:967.

10. De Jong M, Peeters F, Gard T, Ashih H, Doorley J, Walker R, Rhoades L, Kulich RJ, Kueppenbender KD, Alpert JE, Hoge EA. A randomized controlled pilot study on mindfulness-based cognitive therapy for unipolar depression in patients with chronic pain. The Journal of clinical psychiatry. 2018 Jan;79(1).

11. Areeudomwong P, Buttagat V. Reliability and validity of the cross-culturally adapted thai version of the tampa scale for kinesiophobia in knee osteoarthritis patients. The Malaysian journal of medical sciences: MJMS. 2017 Mar;24(2):61.

12. Domenech J, Sanchis-Alfonso V, López L, Espejo B. Influence of kinesiophobia and catastrophizing on pain and disability in anterior knee pain patients. Knee Surgery, Sports Traumatology, Arthroscopy. 2013 Jul 1;21(7):1562-8.

13. Damsgård E, Fors T, Anke A, Røe C. The Tampa Scale of Kinesiophobia: a Rasch analysis of its properties in subjects with low back and more widespread pain. Journal of rehabilitation medicine. 2008 Nov 5;39(9):672-8.

14. Zale EL, Ditre JW. Pain-related fear, disability, and the fear-avoidance model of chronic pain. Current opinion in psychology. 2015 Oct 1;5:24-30.

15. Abdolghadery M, Kafee M, Saberi A, Aryapouran S. The effectiveness of mindfulness-based cognitive therapy (MBCT) and cognitive behavior therapy (CBT) on decreasing pain, depression and anxiety of patients with chronic low back pain. SSU_Journals. 2014 Feb 10;21(6):795-807.

16. Helmhout PH, Harts CC, Staal JB, Candel MJ, De Bie RA. Comparison of a high-intensity and a low-intensity lumbar extensor training program as minimal intervention treatment in low back pain: a randomized trial. European spine journal. 2004 Oct 1;13(6):537-47.

17. Veehof MM, Trompetter HR, Bohlmeijer ET, Schreurs KM. Acceptance-and mindfulness-based interventions for the treatment of chronic pain: a meta-analytic review. Cognitive behaviour therapy. 2016 Jan 2;45(1):5-31. 